Babalola, O., Ibem, E., Adewale, B., Ediae, O., Jegede, F., Eke, W., Adeluoye, O. (2018). Research Methodologies in Architecture Programs in Covenant University, Ota, Nigeria. Submitted in May, 2018 to EDULEARN18 Conference 2-4, July, 2018, Palma de Mallorca (Spain)

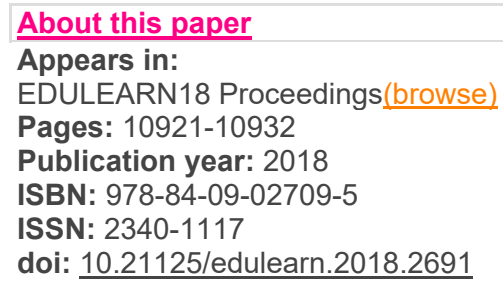

Conference name: 10th International Conference on Education and New Learning Technologies Dates: 2-4 July, 2018

Location: Palma, Spain

Citation download:

(BibTeX) (ris) (plaintext)

Other publications by the authors:

(search)

Buy the publication:

(bookshop)

Upcoming event:

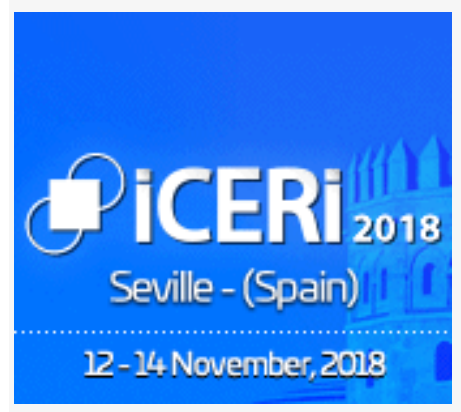

- Announcement

- Registration is open now

\title{
Crossref $\forall$
}

\section{RESEARCH METHODOLOGIES IN ARCHITECTURE PROGRAMS IN COVENANT UNIVERSITY, OTA, NIGERIA}

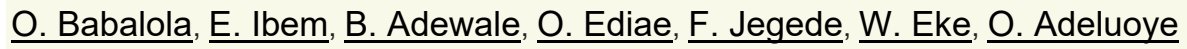

\section{Covenant University (NIGERIA)}

The importance of research methodologies (R.Ms) in accomplishment and development of educational curriculum cannot be over-emphasized. In this study, R.Ms employed in undergraduate and postgraduate studies in Department of Architecture Covenant University Ota, Nigeria were examined. The objectives include examining research methodologies previously employed and currently being employed; establishing the correlation between mastery, knowledge bases and the predominant methodologies 
commonly employed in architecture research programs (Bachelor of Science (B.Sc.) Degree, Master of Science (M.Sc.) Degree, and Master of Philosophy (M.Phil.)/Doctor of Philosophy (Ph.D) Degree in the University. The methodology adopted for the work is the cross-sectional survey of the 153 of the final year B.Sc. and M.Sc., and the Ph.D Students using 5-point Likert Scale questionnaire as data collection instruments; examination of randomly selected 270 of the over 782 dissertations and theses submitted to the Department; and interview of 12 of the students and graduates across the levels. Data obtained from cross-sectional survey; examination of randomly selected dissertations and theses submitted to the Department; and interview of the students and graduates across the levels were subjected to descriptive statistics (such as percentages and frequencies) and inferential statistics (Chi-square and Pearson's correlation). The results showed that majority (33\%) of the previous and current students are mainly quantitative (combined with some elements of observation and interviews), as against the majority which were fully qualitative (including historical, comparative, descriptive and evaluation combined with observation and interviews). The findings from current compared to previous researches showed increased quantitative (correlation) combined with some elements of observation and interviews as against qualitative research. The interviews conducted in this study also corroborated the trend. The study recommended that every researcher be equipped with good understanding of the research classes, designs, domains, methods, theories and paradigms to enable them fashion out appropriate methodologies for specific research projects. keywords: classes, design, domain, methods, paradigm, theory. 